\title{
Research on the International Export Competitiveness of Honey - Taking Anhui Province as an example
}

\author{
Hua $\mathrm{Yu}^{1,2}$, Yanbin $\mathrm{Qi}^{1, \mathrm{a}}$, Yubao $\mathrm{Yan}^{2}$ and Pengbo Cui ${ }^{2}$ \\ ${ }^{1}$ College of Economics \& Management, Sichuan Agricultural University, 611130 Chengdu Sichuan, China \\ ${ }^{2}$ Sichuan Entry-Exit Inspection and Quarantine Bureau, 610041 Chengdu Sichuan, China
}

\begin{abstract}
This article uses the data of honey export from 2000 to 2013 (Jan. to Aug.) to make an analysis on the fluctuation of honey export number and price in Anhui Province in order to know about the current situation of honey export in Anhui Province. Then it quantitatively makes an analysis on the current situation of international export competitiveness of honey in Anhui Province by market share, trade competitiveness index, export quality index and other methods; It also uses the analysis result to find out the relevant factors that affect the international honey export competitiveness and proposes the relevant countermeasures to improve the international competitiveness of honey in Anhui Province.
\end{abstract}

Keywords. Anhui honey; international competitiveness; market share; quality index

\section{Introduction}

The honey contains fructose, glucose, vitamins, minerals and enzyme, and has a high nutritional value, so it is the first choice of consumers. The boundless regional area and abundant honey plants in China prove that it is profitable to develop the honey production in China. As a nutritional food for all ages, the honey is also one of the natural nutritional foods widely used in the world and popular with the consumers in the whole world. Across the Yangtze River and Huai River, Anhui Province has an unique climate condition, sufficient sunlight and fertile lands. It is located in the traffic pivot, having indescribable advantages on bee keeping and bee product trade. The traditionally advantageous produce in Anhui Province-bee product, ranked first in China by its export volume over 18 thousand tons in 2001, accounting for $1 / 5$ of national export volume. Its output value hit 140 million yuan, with foreign exchange earning 16.50 million dollars. But the export volume of honey in Anhui Province was greatly reduced in 2002. Facing the green barrier of several countries in EU, the export volume of honey reduced to 11,800 tons, with export amount also reduced to over 8 million yuan, 35\% lower than that in 2001 . Although the exporter of honey in Anhui Province changed the export strategy, and the government provided a positive support, the export volume in 2003 still reduced to 8,300 tons, hitting the export of honey product

${ }^{\mathrm{a}}$ Corresponding author: qybin@sina.com in Anhui Province hard. Through a series of difficulties, the export volume of honey in Anhui Province much worse than before, and the quality problem is not solved. Plus, due to the development of emerging honey producing countries, the international honey market for honey in Anhui Province is shrinking. Based on the above background, this article analyzes the current situation of trade for the export of honey in Anhui Province to find out the change of international competitiveness advantages, analyze the reasons and propose the advice. It will be of indispensable significance for the development of international bee product trade in China.

\section{Relevant domestic researches on the export trade and international export competitiveness of honey in Anhui prov- ince}

It can reflect the market share, trade competitiveness index, fixed market share model, quality index, export price comparison and other methods for the international competitiveness of honey. Zhu Junbo, Yang Hongmei (2007) ${ }^{[1]}$ The main market share (including international market share and market share for importing countries) and trade competitiveness index are used to analyze and estimate the situation and change trend for international competitiveness of honey in China. Based on his analysis, we find out some factors that affect the international competitiveness of honey in China, such as low exporting price, small scale of production, unstable quality of ex- 
porting honey, etc.. Li Chunjie, Yao Yu (2007) ${ }^{[2]}$ select the estimation index for international competitiveness: Revealed Comparative Advantage index, international market share index and trade concentration index. They think that the main factors that affect the international competitiveness of bee product in China are the change of supply and demand of the international bee product market and the difficulties for bee product in China. Pan Helin, He Minhong (2013) ${ }^{[3]}$ make a factor analysis and make a relevant assessment for the general international competitiveness of honey in China for recent 20 years by taking advantage of the relevant data about the honey trade in China from 1990 to 2009, and indicate that the export of honey in China is facing an intense competition in the international market, and has a lower international competitiveness. While this kind of competitive advantage mainly comes from the high productivity and low price of the exporting honey in China, which, however, is weakening over time.

Through the summary and development of opinions from scholars in each field and based on the actual understanding of international competitiveness and exporting trade of honey in Anhui Province by data analysis, this article starts with solving the problem of weak exporting trade competitiveness of honey in Anhui Province, then uses market share, exporting price comparison, quality index and other methods to analyze the relevant factors that affect the exporting competitiveness of honey, and finally proposes some advice in the hope to make improvement for the international competitiveness of bee product in Anhui Province to re-win the trust of consumers.

\section{Current situation of international ex- porting competitiveness for honey in Anhui province and the reasons}

This article mainly uses market share, trade competitiveness index and quality index to directly analyze and estimate the situation and change trend of international competitiveness for exporting honey in Anhui Province to find out the relevant factors that affect the international exporting competitiveness for honey in Anhui Province.

\subsection{Market share}

Market share is the simplest and directest index to reflect the international competitiveness. It may indicate the competitiveness held by the goods of some regions in the international or domestic market, as well as the degree of international competitiveness. Generally, higher market share indicates stronger competitiveness; otherwise, it will indicate weaker competitiveness.

As in Figure 1, it indicates the change of international market share of exporting honey in Anhui Province from 2000-2012 Among which, the international market share of honey in Anhui Province was greatly reduced in 2002 and 2006. Despite the obvious improving trend of market share in 2000 and 2001, with market share over $3 \%$, it was suddenly reduced to only $2.09 \%$ in 2002 , and to $2.08 \%$ especially in 2003 . The reduction range of market share this time was the historically largest, hitting $48.6 \%$, which was a deadly blow on the export of honey in Anhui Province. In spite of the improvement to $3.44 \%$ in 2005 , it was reduced to $2.35 \%$ again in 2006 , with reduction range $31.7 \%$, which cause a serious loss for the export of honey in Anhui Province. The world market share of honey in Anhui Province was generally improved after 2007 and hit the historical high of 5.2\% in 2012.

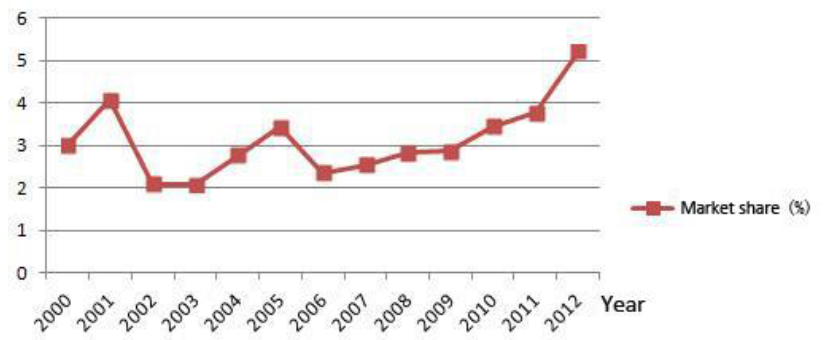

Data sources: International Food and Agriculture Organization statistical database (FAOSTAT).

Figure 1. Global market share of exporting honey in Anhui Province from 2000-2012.

\subsection{Trade competitive index}

Trade competitive index (TC), also called trade specialization factor, signifies the ratio of net export and total export volume of some goods in a country (region). This index is a useful tool for analysis on the industrial international competitiveness, and able to reflect the general comparable advantages situation for the calculated target. It is one of the common indexes to assess the international competitiveness of some exporting product in a country. Its calculation formula is:

$$
T C=(X i j-M i j) /(X i j+M i j)
$$

In the above formula, $X i j$ is the export volume of $j$ th goods in $i$ country (region); Mij is the import volume of $j$ th goods in $i$ country (region); The value range of trade competitive index is $(-1,1)$. If TC index is positive, it'll indicate that the productivity of this kind of product is higher than the international degree, belongs to net export and has a strong international competitiveness. In case of $\mathrm{TC}=1$, the international competitiveness reaches the highest level; If this index is negative, it'll indicate that the productivity of this kind of product is lower than the international degree, belongs to net import and has no international competitiveness. In case of $\mathrm{TC}=-1$, the international competitiveness is in its lowest level; If this index is zero, it'll indicate this kind of goods belong to intra-industry trade, and the competitiveness is almost equal to the international level. In short, the TC index of some products is in corresponding relation with its international competitiveness, and higher index indicates stronger competitiveness.

Figure 2 describes the change of trade competitive index for honey in Anhui Province from 2006 to 2012. We shall realize a very serious problem that since 2006 , the competitive index of honey in Anhui Province has always been in the declining trend. As we said about the corresponding relation of index TC with its international com- 
petitiveness at the beginning, the gradual decrease of the index will signify the gradual weakening of international competitiveness. Especially after 2010, the intenser decline of TC index indicated the reduction of international competitiveness of honey in Anhui Province. This will signify that since 2006, the international competitiveness of honey in Anhui Province kept in the decline trend and with more serious declining range. This phenomenon justifies the significance of improving the international competitiveness of honey in Anhui Province by analysis on the factors that affect the international competitiveness.

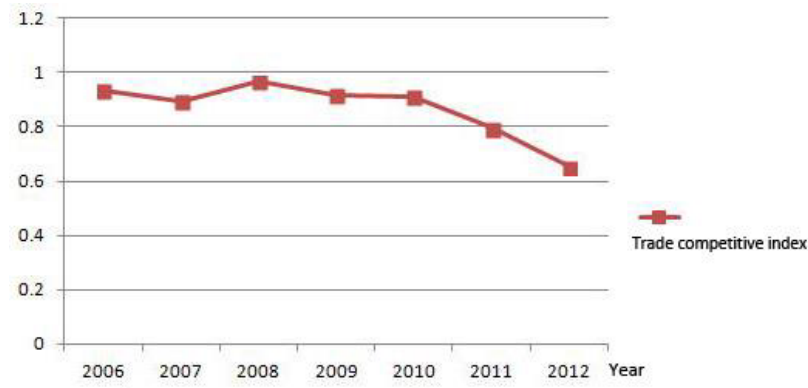

Data sources: Statistical Yearbook of Anhui Province.

Figure 2. Trade competitive index of exporting honey in Anhui Province from 2006-2012.

\subsection{Quality index}

Quality index is the ratio of unit price index and the general index of exporting goods price for some exporting goods in some regions. Generally, if the quality index of exporting goods is increased, it will indicate that the added value of this exporting goods is increasing, namely the quality competitiveness in the international market is increasing; Otherwise, it'll be in the opposite situation. Its calculation formula is:

$$
Q X T N=(P X T N / P X O N) /(P W T N / P W O N)
$$

In the above formula, $Q X T N$ indicates the exporting quality index of nth product in $\mathrm{x}$ region in $\mathrm{t}^{\text {th }}$ year, and $P X T N$ indicates the exporting price of $\mathrm{nth}$ product in $\mathrm{x}$ region in $\mathrm{t}^{\text {th }}$ year. $P X O N$ indicates the exporting price of nth product in $\mathrm{x}$ region in the base period. PWTN indicates the exporting price of $n$th product in $\mathrm{t}^{\text {th }}$ year. $P W O N$ indicates the exporting price of nth product in the base period.

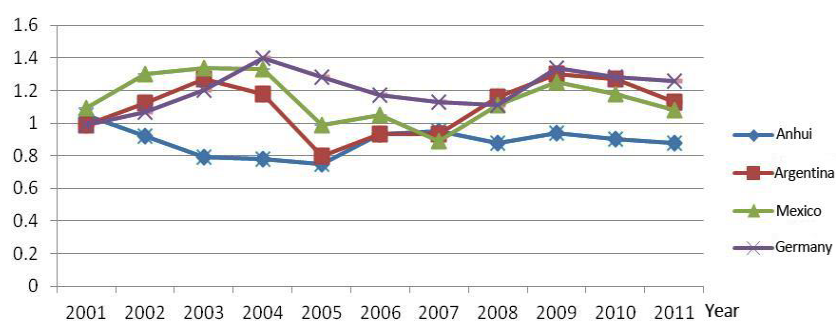

Data sources: FAOSTAT; Statistical Yearbook of Anhui Province.

Figure 3. Quality index change for the honey in Anhui Province and main honey exporting countries in the world from 2001 to 2011.

As in Figure 3, the quality index change for the honey in Anhui Province and main honey exporting countries in the world from 2001 to 2011 was calculated according to the base period in 2000. Among which, Germany has the highest quality index of exporting honey. Its maintenance of quality index over 1 in each year indicated that Germany has strong comparable advantages on the quality index of exporting honey. As we can see in the above figure, the quality index of Mexico was higher than that of Argentina before 2007, but fell behind afterward. In general, the quality index for those two honey exporting countries were almost the same, with the quality index over 1 almost in each year, which indicated that the quality of exporting honey in those two countries was almost the same and had a high quality, as well as had an obvious quality competitive advantages on the honey export. But as we can also see in the above figure, the quality index of Anhui Province is lower than the other countries, which was more obvious from 2001 to 2005 and from 2008 to 2011. It indicates that the exporting honey in Anhui Province is weak in the quality, namely has low quality competitiveness in the international market, and the added value of export for the honey is also low. In summary, we can see from the above analysis that the exporting honey in Anhui Province has no advantages on the quality, and the international competitiveness of exporting honey is reduced due to the quality problem, with the increasing gap in quality compared to other countries.

\subsection{Reasons that cause the above phenomena}

1) Low technical level of production and export quality of honey in Anhui Province Currently, the honey in Anhui focuses on farming production operation, most of which are in the family workshop era. The production, machining, storage and export of honey are often independent and lack the standard control, which give rise to possibility of inferior honey. The small-scale production method fails to improve the productivity for a long time and ensure the quality of honey, which has serious hidden safety troubles. As we can see in Figure 5, the exporting honey in Anhui Province has a low quality and low reputation in the importing countries, especially in UN and other regions. It was returned for multiple times due to excessive content of chloramphenicol and heavy metal, which seriously affect the international competitiveness of exporting honey in Anhui Province.

2) The honey in Anhui Province lacks perfect competition mechanism in export and management Due to the lack of deep survey and general control of international market for most of Chinese exporting enterprises, failure to adjust the price and number of exporting goods in time according to the situation of international market and import countries, and due to the lack of perfect competition mechanism in export and management for honey, the exporters of honey in each province forced the price down to get the control of foreign market, which caused a long-term low exporting price for honey in Anhui Province, but its costs were increasingly higher by years. Therefore, the exporters of honey in Anhui Province purchased the unripe honey with lower price, which made them fall into the vicious cycle and affected the quality of 
exporting honey. Furthermore, few of leading exporting enterprises and the lack of brand product brought an adverse impact on the sustainable development of exporting honey in Anhui.

3) Main import countries of honey carried out "green barrier" on China From 2002 to 2006, China suffered "green barrier" from the import countries. In Jan. 2002, EU increased the standard of residual quantity of chloramphenicol in the importing honey from $5 \mathrm{ppb}$ to $0.1 \mathrm{ppb}$, and laid embargo by reasons that the residual quantity of chloramphenicol in the honey of China was excessive; In Aug. 2002, US FDA increased the standard of residual quantity of chloramphenicol in the importing honey from $5 \mathrm{ppb}$ to $0.3 \mathrm{ppb}$. It not only destroyed and returned the honey with excessive quantity of chloramphenicol, but also put its production enterprises on the list of automatic retention without inspection. This is just a little proportion of "green" barrier, but indirectly caused a large decrease of export volume of honey in Anhui Province from 2002 to 2006 , and in 2003, it constantly reduced to 8,378 tons, the historically lowest record, which even made the international market share of honey in Anhui Province hit the lowest point in those two years. Facing with the sudden "green" barrier, Anhui Province lacked the alert and precaution mechanism, and was weak in the precaution and fast response to the foreign technical barrier, which made the exporting honey in Anhui Province suffer a serious blow and a significant loss.

\section{Countermeasure to improve the inter- national competitiveness of bee product in Anhui province}

\subsection{Implement the high quality and low price system; advocate the production of ripe honey}

The high quality of bee product is produced not detected, so the problem shall be solved in the source. Due to the high productivity, low costs, simple collection working procedure, short time requirement and low purchase price of unripe honey compared to the ripe honey, most of the honey currently in the domestic market is the unripe honey with low quality. Most businessmen tend to purchase the unripe honey with varied quality and low price in batches, and put them into the market for sales by artificial concentration into concentrated honey. The unripe honey has a high content of water and is easy to ferment. It often induces excessive content of saccharomycetes and propanetriol and low nutritional value, which directly causes the bee product to be vulnerable to the prevention of technical barrier in the international market and the exporting price to be lower than the international average level for a long time, as well as to fall in the vicious cycle of low concentration--low quality--low price--low profits. The reason that induces the occupation of unripe honey in the market is that the market guidance in the domestic bee product market is wrong, and the purchase prices of honey are the same despite the concentration, so the quality bee product cannot be realized. There are also many beekeepers that mix the water in the manufactured ripe honey with high-concentration to in- crease the production, and mix the sugar in the dilute honey with insufficient concentration, which cause the market full of low-quality honey. The internal heat reduction, lung moistening and other health functions are almost depleted. There are many fake bee products in the domestic market, and we could only trade the low quality for the low price in the international market.

\subsection{Take preventive measures to establish a precaution and fast response mechanism for perfect technical trade barrier}

Precaution for technical barrier is the function of government, and the strengthening of technical precaution and fast response is an efficient measure for the foreign technical barrier. A perfect information system for technical barrier precaution shall include collection of precaution information, risk assessment, publication and feedback systems. The perfect information system shall be established as soon as possible. The risk assessment of precaution information is directly related to the efficiency of precaution. The governmental department shall screen, sort, analyze and treat the collected information and formulate the corresponding dynamic index system, such as the change of growth rate of exporting bee product, change of market share of exporting bee product in the exporting target countries, change in the price of exporting bee product and the similar foreign products, etc.. The precaution information may be publicized by means of electronic publication, notification, newspaper, news, express, etc.. Different publication and feedback methods have different user coverage. Using flexible methods will make the demander get the information in time more easily. Currently, the publication of precaution information by Internet as the carrier has the advantage of low costs and high efficiency, which shall be vigorously promoted.

Establishment and perfection of precaution information system is still the passive response to the technical trade barrier. In the long run, to change the passiveness into positiveness, we shall also create a Chinese standard adaptable to the market economy and internationalization, while the core of establishing a perfect internationalized standard consists in the construction of technical support capacity. The setting, cracking and surpassing of technical barrier, in essence, is the competition of technical innovation capacity among each country. Therefore, our government shall take the advantage of the methods from EU and other developed countries, attach more importance to the technical trade barrier problem, organize the national scientific resources to provide the powerful technical support for establishment of technical barrier, and propose the technical barrier standard as the strategic countermeasures through a long-term technical preparation.

\subsection{Positively exploit the new market and dis- pense the risk of honey trade}

The purpose of technical barrier is to limit the import volume to protect the domestic industry, and the technical 
standard or regulations used shall be stricter than the previous or regular standard, which may induce an excessively high costs or longer cycle for the improvement costs of product quality. If the exporting enterprises keep putting the product in the market, the short-term export volume will be definitely subject to serious decline and significant loss. So, facing the over-high technical standard, the exporting enterprises shall positively exploit the new market, so that the export volume will not be greatly reduced in the transitive period of improving the product quality.

Furthermore, the government shall make use of the "green box" policy and increase the infrastructure investment to provide more support for the honey industry and the legal assistance to jointly deal with the technical barrier and maintain the legitimate rights for beekeepers and honey traders.

\subsection{Strengthen the brand construction and in- crease the added value of product for exporting honey in Anhui Province}

For all the time, the exporting honey in Anhui Province depends on the low price as its main competitiveness. While with the increase of exporting costs and constant increase of price, the previous competitiveness of low price is seriously impacted. If keeping the price fighting, it'll only greatly reduce the profits of honey exporting enterprises or even make them run at a loss or be unable to ensure the quality of exporting honey. So, in such case, the honey in Anhui Province may only resort to other competition methods to improve the international competitiveness of bee product.

To establish a normal exporting order, the exporting enterprises shall establish the brand strategy and operation integrity to deepen the understanding of international market about the bee product industry and enterprises so that the future market development space based on the integrity will be wider and endurable.

\section{Acknowledgement}

National Social Science Foundation Project "Research on the Problem of Agricultural Production Mode under the Visual Threshold of Agricultural Product and Food" (GN:14XGL003): Scientific Plan Project of National Bureau of Quality Inspection "Research on Measures of Exported Port against the Technical Trade Barrier" (GN: 2014IK242): Scientific Plan Project of Sichuan Province "Research on Improvement of Sichuan Export Agricultural Product Quality Competitiveness" (GN: 2014ZR 0118): Sichuan Key Scientific Self-financing Project in 2012 (GN: 2012ZRZ014, 2012SZZ030); Scientific Project of Sichuan Entry-Exit Inspection and Quarantine Bureau in 2013 (GN: SK201314).

\section{References}

1. Zhu Junbo \& Yang Hongmei. Analysis on the international competitiveness of honey trade in China [J]. Anhui Agricultural Science, 2007, (03):6305-6306.

2. Li Chunjie \& Yao Yu. Comparison and analysis on the international exporting competitiveness for bee product in China [J]. Journal of Yunnan Finance and Trade Institute, 2007, (04):21-23.

3. Pan Helin \& He Minhong. Analysis on the international exporting competitiveness of honey in China [J]. Statistics and Decision, 2013, (05):136-138.

4. Song Yong. Route to breakthrough the exporting technical trade barrier for honey--Taking the exporting trade of honey in Anhui as the example [J]. Journal of Chongqing Normal College (Social science edition). 2011, (11):95-99.

5. Huang Tian. Green technical barrier in the exporting honey in Anhui province and countermeasure [J]. Northern Trade. 2011, (04):9-11.

6. Shen Yang. Countermeasure and advice on the breakthrough of green trade barrier for bee product in Anhui province [J]. Anhui Agricultural Science. 2004, (08):813-814.

7. Hui Xinghui. Analysis on sustainable development strategy for bee product in China [J]. China Bee Industry. 2011, (Z9):32-34.

8. Chen Zhenqi. Impact of Japanese new listing system about importing honey on the Chinese beekeeping industry [J]. Bee Magazine. 2006, (04):4-5.

9. Qi Yamei \& Ye Zhihua. analysis on the export and blocking factors for Chinese bee product [J]. China's Livestock Industry. 2012, (12):19-23.

10. Liu Pengfei \& Li Haiyan. Empirical analysis on the impact of technical barrier on domestic honey export [J]. International Trade Problem. 2010, (11):99-104.

11. Gao Yun. Research on Chinese honey trade and trend prediction [J]. China Bee Industry. 2012, (12): 44-46.

12. Wang Qin. Review of contemporary international competitiveness theory and assessment system [J]. Foreign Social Science. 2006, (06):33-38.

13. Shuai Chuanmin. Assessment of international competitiveness for chinese produce [J]. Management World. 2003, (01):97-103.

14. Liu Qingbo \& Liu Junchang. Analysis on the comparable advantages and affecting factors about domestic honey trade [J]. Journal of University of International Business and Economics. 2012, (05):13-22.

15. Huang Tian \& Gao Qian. Reason and countermeasure of impact of green technical barrier on exporting honey in Anhui [J]. Heilongjiang Foreign Trade. 2011, (02):40-41. 